\title{
Multimodal Study of Adult-Infant Interaction: A Review of Its Origins and Its Current Status ${ }^{1}$
}

\author{
Soledad Carretero Pérez ${ }^{2}$ \\ Consejo Nacional de Investigaciones \\ Científicas y Técnicas, \\ Buenos Aires, Argentina
}

\author{
Silvia Ana Español \\ Consejo Nacional de Investigaciones \\ Cientificas y Técnicas, \\ Buenos Aires, Argentina
}

\begin{abstract}
An interpretative review of research on adult-infant interactions involving the analysis of movement behaviors is presented, systematically linking previous studies to current research on the subject. Forty-two articles analyzing the dyad's interactive movement in the period 1970-2015 were found. Twelve papers were excluded, including only those that studied the phenomenon in the baby's first year of life. The results revealed that movement was a central topic in early interaction studies in the 70s. In the 1980's and 1990's, its study was marginal and it is currently resurging under the embodiment perspective. The conceptual framework and research methods used in the pioneering work are presented, and the thematic foci shared with current research are highlighted. Thus, essential keys are provided for the updated study of early interactions from a multimodal perspective.
\end{abstract}

Keywords: adult-infant interaction, development, movement, social play, communicative musicality

\section{Estudo Multimodal da Interação Adulto-Criança: Uma Revisão de Suas Origens e Seu Status Atual}

\begin{abstract}
Resumo: O objetivo desta revisão é apresentar os antecedentes da investigação do movimento em interações adultos-bebês durante o primeiro ano de vida e relacioná-los sistematicamente com os trabalhos atuais na área. Foram encontrados 42 artigos que analisam o movimento interativo da díade no período de 1970-2015. Foram excluídos 12 estudos, incluindo apenas aqueles que estudaram o fenômeno no primeiro ano de vida do bebê. Os resultados revelaram que o movimento foi um tema central em estudos de interações iniciais mãe-bebê na década de 1970. Nas décadas de 1980 e 1990, seu estudo foi marginal e atualmente está ressurgindo na perspectiva do embodiment. Assim, são apresentados o quadro conceitual e os métodos de pesquisa utilizados no trabalho pioneiro, destacando-se os focos temáticos partilhados entre eles e a pesquisa atual. Deste modo, proporcionam-se chaves essenciais para o estudo atualizado de interações iniciais a partir de uma perspectiva multimodal.
\end{abstract}

Palavras-chave: interação adulto-bebé, desenvolvimento, movimento, jogo social, musicalidade comunicativa

\section{Estudio Multimodal de las Interacciones Adulto-Bebé: Una Revisión Sobre Sus Orígenes y Su Estado Actual}

\begin{abstract}
Resumen: El objetivo de esta revisión es exponer los antecedentes de investigación del movimiento en interacciones adulto-bebé durante el primer año de vida y vincularlos sistemáticamente con los actuales trabajos sobre este tópico. Se encontraron 42 artículos de análisis del movimiento interactivo de la díada en el periodo 1970-2015. Se excluyeron 12 trabajos, incluyendo sólo los que estudiaron el fenómeno en el primer año de vida del bebé. Los resultados revelaron que el movimiento fue un tópico central en estudios sobre interacciones tempranas en los años 1970, en las décadas del 1980 y 1990 su estudio fue marginal y actualmente está resurgiendo en el marco del embodiment. Se presenta el marco conceptual y los métodos de investigación utilizados en los trabajos pioneros y se destacan los focos temáticos compartidos entre éstos y las actuales investigaciones. De este modo, se brindan claves esenciales para el estudio actualizado de las interacciones tempranas desde una perspectiva multimodal.
\end{abstract}

Palabras clave: interacción adulto-bebé, desarrollo, movimiento, juego social, musicalidad comunicativa

The study of the early interactions established between adults and infants is an ongoing research topic in

\footnotetext{
${ }^{1}$ Paper based on the doctoral dissertation in Psychology of Prof. Soledad Carretero Pérez: "Bodily contact in early interactions of communicative musicality", under the advice of Silvia Español, Ph.D. and co-advice of Favio Shifres, Ph.D., defended on March 21, 2016, at Universidad Nacional de Córdoba.

Support: This research received funding from Consejo Nacional de Ciencia y Técnica and Research Projects PICT of the Agencia Nacional Promoción Científica y Tecnológica.

${ }^{2}$ Correspondence address:

Soledad Carretero Pérez. Ayacucho 555, C1026AA. Buenos Aires, Argentina. E-mail: solecarretero@gmail.com
}

developmental psychology (Bornstein \& Tamis-LeMonda, 2010; Lieven \& Stoll, 2013; Trevarthen \& Aitken, 2001). The most studied elements of these interactions have been facial expression, vocalizations and exchanges of eye contact (Stern, 2010; Beebe, 2014). A large number of research areas have continued to focus on this type of conducts since the 1970's until today, but the study of movement followed a particular course: in the 1970's, it was considered a core topic to understand the organization of adult-infant interactions but, afterwards, it only continued beyond the main research currents (Stern, 2010; Bebee, 2014; Jaffe, Beebe, Feldstein, Crown, \& Jasnow, 2001). Given this trajectory, the contemporary investigation of movement is uprooted from its 
original proposals. There is a gap between the pioneering studies (Bateson, 1971; Beebe \& Gertsman, 1980; Condon \& Sander, 1974; Fogel, 1977; Stern, 1974a, 1974b; Stern, Beebe, Jaffe, \& Bennett, 1977) and contemporary research (Dissanayake, 2000; Fogel \& Garvey, 2007; Malloch \& Trevarthen, 2009; Negayama et al., 2015; Reddy, 2008; Thelen, 2000). Some current studies that analyze early interactive movement mention the pioneering studies as antecedents (Delafield-Butt \& Trevarthen, 2013, 2015; Gratier \& Apter-Danon, 2009; Needham \& Libertus, 2011), but there is a notable lack of systematics in the references and in the relations established between the theory and the former and current empirical data.

This study intends to bridge that gap by presenting a review of the study of movement and of the articles that adopted a multimodal perspective in the study of early interactions, from the start until today. With a view to establishing solid links among them, each article or group of articles is presented in a context, indicating the intellectual climate of the period, its main intellectual influences and repercussions in the field.

Socio-cognitive and communicative development rests on the first interactions between adult and infant (Bornstein \& Tamis-LeMonda, 2010; Delafield-Butt \& Trevarthen, 2015). They are a basic condition for development. Therefore, understanding the organization modes of adultinfant interactions represents one of the great challenges in developmental psychology. Nowadays, embodiment theory is an alternative perspective to classical cognitive psychology, which defends that the adjustment processes to the social context and the body's role in them are keys to understand complex psychological processes (Johnson, 2007; Needham \& Libertus, 2011; Delafield-Butt \& Trevarthen, 2015). In view of the predominantly kinesthetic nature of experience in the first years of life, the field of early development particularly needs further depth in the embodied perspective of cognition, and this research area includes studies on adult-infant interactive movement. The objective in this review is to present the research antecedents of movement in adult-infant interactions during the first year of life and systematically link them with current studies on the theme.

\section{Method}

An interpretative review focused on qualitative studies was undertaken. The aim was to achieve a scientifichumanistic interpretation of the theoretical perspective and the results of past work (Cooper, Hedges \& Valentine, 2009; Fernández-Ríos \& Buela-Casal, 2009). Most of the studies under review are qualitative or mixed. The primary objective was to analyze the studies concerning movement in the adultinfant interactions, discussing how they have developed from the start until recently, with a view to enriching the emerging multimodal perspective in early interaction studies.

\section{Procedure}

Data collection. The bibliographic search was undertaken in the main databases used in the area: Eric (Scopus and Proquest), PsycINFO, PubMed, ScienceDirect,
Web of Sciences, Dialnet, Sci, Latindex and Psicodoc, through the following keywords: adult-infant interaction, movement, early interaction. The inclusion criteria used were: articles or book chapters published in English, in the period 1970-2015, which analyzed the interactive movement adult-infant in the infant's first year of life. The exclusion criteria were as follows: articles in other languages that were focused on other phases of development.

Data analysis. The requisites for interpretative reviews were taken into account (Fernández Ríos \& Buela Casal, 2009). First, the viewpoints of different authors were compared and the studies were grouped in function of their theoretical perspectives to be able to identify relations, contradictions, gaps and inconsistencies in the literature on the theme. That is one of the fundamental objectives of a review (American Psychological Association, 2001/2002). Second, a reflection was undertaken from an interdisciplinary perspective, considering the relations of the pioneering studies of movement with different adjacent fields of study, such as ethology, nonverbal communication and anthropology. Finally, the themes and results found in the articles under review were related with the current state of the art of the theme.

\section{Results}

Forty-two articles were found, 30 of which studied the phenomenon in the infant's first year of life; 7 were published in the 1970's, 2 in the 1980's and 2 in the 1990's; 20 since the year 2000 until date. Next, first, the pioneering studies and the intellectual climate they emerged in are detailed; then, a research area is presented that sustained the study of movement, despite the move from the main research currents; and thirdly, it is highlighted how the microanalysis was constituted in the predominantly chosen method; finally, the recent emergence of new studies on movement in early interactions is discussed.

\section{The Pioneering Studies and the Intellectual Climate in the 1970's}

In the 1970's, the research on early development experienced exponential growth, specifically research on early social skills and adult-infant interactions. The pioneering studies that focused on the interactive movement between adult and infant represented a minority in relation to the studies focused on other aspects. These received influence from three academic fields: non-verbal communication, etology, and adult verbal communication.

The studies by Catherine Bateson and William Condon. A widely used term to describe the adult-infant interactions in the 1970's was face-to-face interactions (Jaffe et al., 2001), a name that evidences the linguistic stamp placed on these studies. The most analyzed behaviors in those studies were the same that stood out in the analysis of adult conversations: sounds, facial gestures and eye contact. The studies by Bateson $(1971,1979)$ on protoconversations and the work by Condon and Sander (1974) on interactive synchrony, however, differed from this major trend. 
The work of Catherine Bateson was influenced by her educational background in the kinesics perspective on nonverbal communication, created by the anthropologist Ray Birdwhistell (Bateson, 1975a, 1975b, 1979). This focus studied facial expressions, gestures, postures and movements in humans that transmit meanings in different communicative contexts through the systematic observation of video recorded interactive scenes. Bateson (1971) statistically analyzed the temporal structure of a mother and infant's vocal exchanges between the first and third month of life, proving that the alternating pattern was predominant. One of the reasons for the wealth of Bateson's pioneering work was that she introduced an anthropological perspective in a psycholinguistic research team - Margaret Bullowa's team. That anthropological view allowed Bateson to consider the dyad's incipient vocal exchanges as a teaching-learning scene of the rules of conversation.

On the other hand, Condon $(1970,1976)$ - one of the drivers of the non-verbal communication field, together with Birdwhistell - led the research on interactive synchrony (Condon, 1970, 1976, 1980; Condon \& Ogston, 1966, 1967; Condon \& Sander, 1974) and introduced a methodological innovation. The predominant method in kinesics was the observation of extensive recordings of human interactions (Birdwhistell, 1952; Kendon, 1972). Condon and Ogston $(1966,1967)$ proposed the microkinesics procedure: the detailed analysis of just one or two minutes. Using this strategy, they described the interactive synchrony that can be observed in adult verbal interactions: the correspondence between the elements in a speaker's discourse and the interlocutor's movements, that is, the changes in the listener's body movements are timed to the changes in the speaker's phonetics, syllabi, words, accentuation and rhythm. Interactive synchrony corresponds to a precise exchange of micro-movements danced between the speaker and the listener. Later, Condon and Sander (1974) developed a study that was both famous and polemic: they found interactive synchrony between adults and infants by applying the microkinesics method. The infants' type of movement - flexion-extension, pronation-supination or adduction-abduction - and the joint they moved were analyzed using a frame by frame projector. They found correspondences between the movements of 16 infants and the changes in their mothers' phonetics, syllabi, words, accentuation and rhythm of speech. The authors suggested that the exchanges between adult and infant were similar to an interactive dance. The correspondence was found when the stimulus granted to the infants was an adult talking or an audio recording of the human speech. It was suggested that the infants distinguish speech from other types of sounds and organize their movement in response to the speech.

The work by Condon and Sander received harsh criticism and most of the scientific community questioned its results. On the opposite, Bateson's studies on protoconversations were widely accepted and the term continues until today (Kokkinaki, 2010; Malloch \& Trevarthen, 2009). The way Bateson described the interactive phenomenon was probably more in line with the intellectual climate of the period: a scene in which the mother taught verbal exchange skills, in which behavioral patterns characteristic of adult conversations are practiced: the alternation of vocal shifts, mutual eye contact and facial responsiveness.

Although the study by Condon and Sander (1974) was widely criticized, it has always been cited in studies on preverbal communication. The hypothesis of interactive synchrony intuitively seemed attractive and discoveries of infant's early perceptive skills (Gibson, 1969) turned it into a theoretically possible phenomenon. That study is an unavoidable predecessor of current studies in the area, as: (a) in the study, interaction was not approached as a face-to-face phenomenon, but the infant's body was considered as a whole; (b) the temporal organization observed was interactive synchrony, a temporal organization that does not define dialogue - marked by the alternation of the time to speak - but other human activities involving full body movement, such as dancing; and (c) Gibson's theory that made it theoretically feasible - the idea that the infant's senses are unified since birth and that perceptive development is characterized by a progressive and increasing distinction of stimulation levels - was confirmed in multiple experiments (Meltzoff \& Borton, 1979; Spelke, 1979) and opened a prolific research area in the 1980's that continues until date (Bremner, Lewkowicz, \& Spence, 2012).

The first studies by Daniel Stern. Stern took interest in the detailed study of mother-infant interactions in their daily context, inspired by etological studies that analyzed the communicative value of animal behaviors in their ecologic midst, paying attention to their form, sequence and temporality (Beebe, 2014; Stern, 1977). The etological studies on human development (for example Hinde, 1974; Konner, 1972) strongly influenced research on child psychological development in the 1970's (Perinat, 1980). The above mentioned microkinesics studies also marked the methodological approach of Stern and his collaborators (Beebe, 2014; Stern, 2010). The first microanalyses by Stern and his team were intended to describe the interactive behavioral patterns and the internal structure of the adult stimulations offered to the infants.

Stern (1974a) analyzed the observable patterns of eye contact between a three-month-old infant and his mother. In that scene, the failure to achieve mutual eye contact was evidenced. To understand the interactive behavior, Stern analyzed, besides the eye contact patterns, the sequences of the mother and infant's movements, inseparable from the action of looking: the orientation of the head, the orientation of the body and the upper limb movements. That study can be considered as the first micro-analytic work that took into account the bodily movement as a relevant behavior to understand the adult-infant relational patterns in the psychology field. In his next research, Stern (1974b) discovers that adult behavior in playful interaction with an infant is structured in definable units. The study included 24 dyads of infants between three and four months old. It is observed that the adult's objective in early social play is to keep up a certain level of attention and excitement in the infant, with a view to manifestations of positive social behaviors. The smallest units of adult behavior were called maternal acts; these acts are combined to constitute more 
extensive units, play sequences and, in turn, several play sequences constitute a broader unit, the full play episodes. The maternal acts contain speech directed at the infant, exaggerated facial expressions and movements the mothers make in front of the infants to attract their attention. Studies in which the dyads were filmed at home started to become more attainable in this decade based on the increasing availability of the technological means needed. Stern (1977) defined the perspective he developed with his team in the 1970's as a combination of human ethology and psychology with microanalytical techniques.

The research group led by Stern and Beebe also received influence from studies about verbal communication, as all of them participated in the team of Joseph Jaffe, who had developed a model to analyze verbal interaction patterns (Jaffe \& Feldstein, 1970). Through this model (Feldstein \& Welkowitz, 1978; Jaffe $\&$ Feldstein, 1970), the phenomenon of vocal congruence was described: in their conversations, the speakers tend to equal the length of their interventions and pauses with that of their interlocutors. This model included a computerized device for the analysis of conversation rhythm. Stern and Beebe worked at the same time in Jaffe's team and in the observation of the nonverbal aspects of mother-infant communication.

\section{The Consolidation of a Research Area}

The linguistic signature prevailed in the 1970's, 1980's and 1990's in the dominant research on early interactions. Most studies remained focused on vocal exchanges and the alternating shifts in speech as the basic mode of temporal organization of interactions. Nevertheless, Stern and Beebe stayed interested in the kinesthetic component and in the idea of the multimodal nature of the interaction. This alternative research area, in which maternal stimulation was studied as a whole of vocal, kinesthetic, facial and tactile behaviors, focused on two research topics: the temporal organization of interactions and the segmentation of behavior into units for study purposes. Although both topics are closely linked, for the sake of clarity, they will be presented separately.

Structural organization: Multimodal units. Proceeding with Stern's work (1974b), the team by Stern and Beebe continued inquiring on the structure of maternal stimulation and included the combined analysis of different maternal behaviors. Therefore, they started to deploy a multimodal analysis.

In 1977, Stern, Beebe, Jaffe, and Bennett analyzed the organization into units and the temporal structure of interactive games with three-month-old infants. The observed behaviors were vocalizations, head movements, facial gestures, tactile behaviors and wide kinesic behaviors. Although the data on tactile and wide kinesic behaviors were not published, the planning of their analysis indicates the interest in movement and bodily contact present in that study. The published data - like the data obtained in Stern (1974b) - showed an organization of vocalizations and movements in three progressively large units: phrases that are repeated to constitute sequences and sequences that constitute episodes of sustained involvement. In addition, they observed that the behaviors of movement were grouped in kinesic phrases and the vocalizations in vocal phrases. Both kinds of phrases did not always occur synchronously, but showed the following shared characteristics: (a) the frequency of their occurrence in the interactions was similar; (b) their structure took the form of bursts and pauses with very similar temporality: in both, the average pause was considerably longer than the average burst, and (c) both types of phrases appeared in combination as well as independently; therefore, they could be considered autonomous communicative acts.

Further on, Beebe and Gertsman (1980) end up establishing the idea of parental stimulation as a multimodal package of behaviors, through a correlation study that offered evidence on the covariance between maternal multimodal behaviors and the infant's level of involvement in the interaction. The results evidenced that the packages of maternal behaviors vary systematically with the infants' level of involvement and, therefore, they concluded that these are specifically communicative. This research supposed a qualitative leap in the incipient multimodal studies.

Temporal organization: Synchrony and alternation. Temporal organization is one of the classical research topics in early interactions. The team of Jaffe, Stern and Beebe created a research line on the theme (Beebe, Lachman, \& Jaffe, 1997; Jaffe et al., 2001). In studies in the area, it had been high highlighted that the temporal organization of the movement interactions was synchronous, while the temporal organization of the vocal exchanges used to be alternated (Bateson, 1975b; Brazelton, Koslowski, \& Main, 1974). In 1975, Stern, Jaffe, Beebe and Bennett investigated whether the synchronous organization was exclusive to the movement behaviors. Remarkably, they found that, in interactions with infants between three and four months, simultaneous vocalization predominated over alternated vocalization and they found a synchronous organization in exchanges of smiles and eye contact. Thus, it was documented that both types of temporal organization can be observed in different types of adult-infant interactive behaviors.

In 1979, Beebe, Stern and Jaffe also turned to the study of the temporal organization of movements. They used categories to analyze the head, body, arm, hand and facial movements. Proceeding with the previous article (Stern et al., 1977), they found patterns of simultaneity and alternation in the movements as well as in the vocalizations. In addition, in both conducts, the mother's trend to interact over longer periods was observed when the sequences were simultaneous, which generated the dyad's trend to simultaneity. Based on these studies, the idea took form that, in the early interactions, simultaneity is a form of temporal organization as important as alternation.

Another fundamental contribution of the 1970's concerning the temporal organization of early interactions came from Fogel (1977), who demonstrated that, depending on the focus of the observation, it can be observed that multiple temporal patterns happen at the same time in an interaction. Fogel found synchronous interactive patterns between different behavioral modalities in a dyad between one and four months of age: between the movements of the 
mother's mouth and head and the infant's mouth movements; between the movements of the mother's mouth and the infant's gaze. It was concluded that, in early interactions, many types of simultaneous temporal organizations are possible between the multiple behaviors of mother and infant: synchrony, alternating shifts, joint start, framing, etc. The author's work offered empirical evidence to reveal the infertility of the discussion about which temporal organization is predominant in these interactions.

Finally, one of the few studies that focused on the multimodal dynamics of interaction in the 1980's came from Beebe, Feldstein, Jaffe, Mays and Alson (1985), in which they analyzed the bilateral regulation mechanisms between mother and infant in vocal and kinesthetic behaviors. 15 dyads with four-month-old infants were studied. The data evidenced-that the temporal synchronization was organized very distinctly in each of these behavioral modalities: in the vocalizations, the more one of the participants vocalized, the more the interlocutor did so; in the kinesic behaviors, on the other hand, a mechanism of regulation by compensation was observed: each participant compensated the increase or decrease in the activity level of the dyad in function of the interlocutor's activity level: the more one of the participants moved, the less the other moved.

\section{The Microanalysis in the Studies of Early Interactions}

The Microanalysis studies in the field of early interactions research, like in other research areas on social exchanges (Bull, 2003). Its choice implies interest in the study of communication as it happens in its original context and the consideration that the interactive situations are multidimensional (Kendon, 1972). As mentioned, the origins of this method go back to the systematic observation of long hours of videos in the fields of communication and anthropology in the 1950's and 1960's. Later, Condon and Ogston (1966, 1967) invented microkinesic observation and Condon used this method in his studies on interactive synchrony; in the second half of the 1970's, the method had gained popularity under the name of microanalysis. This method involves a detailed description of the interactive conducts observed frame by frame in a video taking few minutes, extracted from longer interaction scenes. Such detailed analysis permits observing organization modes of conduct that are not evident to naturalistic observation.

As from the 1980's, most researchers almost abandoned multimodal microanalysis, as the technological tools to work with this method remain crude: projectors were available to watch the video slowly, but the analysis of movement was still done manually. In contrast, the sound analysis techniques gained sophistication. That is one of the reasons why, according to Jaffe et al. (2001), in the next decades, the microanalytic studies of sound in the dyad's interaction are enhanced, while the analyses of movement and multimodal analyses are abandoned. In the microanalyses of vocal exchanges, the study of the reciprocity and temporal organization of adult and infant behaviors remained a research topic and the complexity of its temporal and structural organization was established, as well as the relevance of the rhythmic coordination of the dyad's behaviors for the infant's cognitive development and bonding. Nevertheless, movement only regained interest in the central areas of research on early interactions in the $21 \mathrm{st}$ century. One of the most relevant exceptions on this trend is Fogel's work in the 1990's, who proposed linking the science of movement and developmental psychology and studied the changes that can be observed in the infant's gaze in function of the mother's postural changes (Fogel, 1992; Fogel, Dedo, $\&$ McEwen, 1992). No continuing research line could be developed in that sense though.

\section{The Resurgence of the Study of Movement in the 21st Century}

The regained interest in movement in a widely visible research current emerges in the framework of embodiment in the last two decades. From that perspective, it is considered that mental activity emerges from the bodily interactions with the environment, continuously crimped with perception and action, and that cognition depends on the experiences deriving from having a body with particular perceptive and motor skills (Johnson, 2007; Needham \& Libertus, 2011; Thelen, 2000). In the social cognition field, the secondperson perspective (Gomila, 2003; Pérez, 2013; Reddy, 2008) and the dialogical perspective (Fogel \& Garvey, 2007) also advance by replacing the body in movement to the center of subjective and intersubjective life. Due to space limitations, we will only mention some current studies on movement in the adult-infant dyad: studies on the bodily patterns for intersubjective exchange in different cultures, studies that analyze the target-oriented actions the adults perform in front of the infant, studies that investigate the subjective self-development through preverbal interaction formats, and studies on early communicative musicality.

Some researchers argue that certain daily action patterns and the exchange of objectives, motives and feelings that guide them constitute the base of cultural and embodied knowledge on how to establish intersubjective exchanges in a given culture (Delafield-Butt \& Trevarthen, 2015). In that framework, Negayama et al. (2015) analyzed the intersubjective bodily involvement between adult and infant in daily actions in Scottish and Japanese mothers with their infants between six and nine months of age and found cultural differences in the intersubjective movement keys. In another framework, Brand, Baldwin and Ashburn (2002), Koterba and Iverson (2009) and Licata et al. (2014) found that, in their interactions with infants over eight months of age, the mothers modify and simplify their movements. These modifications could help the infants to understand human target-oriented action. From a dialogical perspective, Fogel, de Koeyer, Bellagamba and Bell (2002) describe how an infant constructs his/her self in dialogue with others through bodily interaction formats. Finally, in the studies of communicative musicality - which refers to the human capacity to sympathetically link up with the interlocutor's motor and sound gestures (Malloch \& Trevarhen, 2009) - themes discussed in the pioneering studies reviewed in this articles are recovered and 
these studies are indicated as direct antecedents. In this field, interactive movement is analyzed as expressive movement accomplished to share mutual experiences. Dissanayake (2000, 2009) and Gratier and Apter-Danon (2009) suggest that there are antecedents of the temporal arts (music and dance) in the way adults spontaneously act upon the infants: they develop a dynamic, rhythmic and multimodal modeling of their behaviors, composing a performance in which the kinesthetic components, sounds and vocalizations constitute sound/kinesthetic units of meaning that are widely repeated. Español and Shifres (2015) analyze the adult performance, using analytic categories and methods from studies in music performance and modern dance. Like in the pioneering studies reviewed, they study the structural and temporal organization of early interaction through microanalysis.

In his most recent book, Stern (2010) proposes the concept vitality forms to capture how the human mind deals with dynamic experiences, which are crucial for interpersonal encounters and performance arts (like music and dance); and redefines the social play between adult and infant as a context in which the adult, through his/her multimodal performances, playfully manipulates the vitality forms. Español, Martínez, Bordoni, Camarasa and Carretero (2014), and Español, Bordoni, Martínez, Camarasa and Carretero (2015) define early social play as the parental playful manipulation of the vitality forms. In the same framework, Martínez (2014) discovers the presence of preconceived images-schemes structures that constitute cognition based on the activity of our bodies in the environment (Lakoff \& Johnson, 1980) in adult action in front of infants and highlights the esthetic elaboration of the component sounds and movements.

\section{Discussion}

The studies by Bateson (1971, 1979) and Condon and Sander (1974) were the first studies to diverge from the preponderant trend to study the conducts that can be observed in the participants' face. These researchers' adoption of an alternative perspective was certainly due to the influence they received from studies about non-verbal communication, which situated the body in movement as a protagonist of human interactions. During the next decades, the few studies that focused on movement in early interactions rested on three academic fields. From ethology, they took the orientation towards studies developed in their daily context; from the non-verbal communication field, the consideration of the intersubjective strength of movement and action exchanges; and from verbal communication studies, the analysis methods of the temporal organization of behaviors. The pioneering studies that in the 1970's analyzed the sounds and movements in maternal behavior focused on two research topics: the temporal organization of interactions and the segmentation of behavior in units for their study. Stern et al. (1975) demonstrated the value of synchrony in early interactions; Beebe et al. (1979) showed that, in exchanges of movements, synchrony was predominant over alternation, and Fogel (1977) illustrated that multiple forms of temporal organization exist together in the interaction.
The studies by Condon and Sander could be considered as the first intent to study the strength of the body in movement in the construction of intersubjectivity among human beings, a proposal present in current studies on early interactions in the framework of embodiment. Although the term multimodality was not used in the studies by Stern et al. (1975), Beebe et al. (1979), and Fogel (1977), these could retrospectively be considered as the first studies in which an exhaustive multimodal focus is outlined. The multimodal focus of early interactions is today an expanding analysis mode in the field of embodiment.

Nowadays, in communicative musicality studies within the framework of embodiment, some of the pioneering studies are appointed as research antecedents, although without establishing systematic theoretical and empirical bonds. Nevertheless, the thematic and methodological convergence is noteworthy. The current research topics are still the temporal organization of interactions and the segmentation of behavior into units. And microanalysis is also selected today as a suitable mode to address the study of multimodal interaction between adult and infant.

The quality and quantity of emerging studies in the broad framework of embodiment suggests that it will increasingly influence studies on human cognition and interaction. Due to the non-verbal and predominantly kinesthetic nature of human experience in the first years of life, the field of early development is in particular need of further elaboration from the embodied perspective of cognition in all of its manifestations. The present review describes a boom in the study of movement, before the current phase, whose conceptual wealth and empirical results had not been systemized thus far. The embodiment perspective of cognition creates the possibility for a new approach to development and faces the challenge of offering new theories on the onset of cognition. This review could favor theoretical development on the embodied psychological processes involved in adultinfant interactions.

This review was restricted to studies on the infant's first year of life that actually analyze the interactive movement of the dyad. The inquiry could expand to research that focused on the study of the infant's solitary movements that can indirectly be relevant for the study of interaction as well. The search for antecedents could also extend to articles that analyze the interactive movement in the infant's second year of life. Finally, another limit in this review could originate in the choice of the keywords: the inclusion of related terms, such as motor development, could offer new information and improve the task performed which, in our opinion, can constitute an important tool for the study of early interactions from a multimodal perspective.

\section{References}

American Psychological Association (2002). Publication manual of the American Psychological Association. Washington, DC: American Psychological Association.

Bateson, M. C. (1971). The interpersonal context of infant 
vocalization. Quarterly Progress Report of the Research Laboratory of Electronics, 100, 170-176.

Bateson, M. C. (1975a). Mother-infant exchanges: The epigenesis of conversational interaction. Annals of the New York Academy of Sciences, 263, 101-113. doi:10.1111/j.1749-6632.1975.tb41575.x

Bateson, M. C. (1975b). Linguistic models in the study of joint performances. In M. D. Kinkade, K. L. Hale, \& O. Werner (Eds.), Linguistics and anthropology: In honor of C. F. Voegelin (pp. 53-66). Lisse, Belgium: Peter De Rider.

Bateson, M. C. (1979). The epigenesis of conversational interaction: A personal account of research development. In M. Bullowa (Ed.), Before speech: The beginning of interpersonal communication (pp. 63-78). Cambridge, UK: Cambridge University Press.

Beebe, B. (2014). My journey in infant research and psychoanalysis: Microanalysis, a social microscope. Psychoanalytic Psychology, 31(1), 4-25. doi:10.1037/ a0035575

Beebe, B., \& Gerstman, L. J. (1980). The "packaging" of maternal stimulation in relation to infant facial-visual engagement: A case study at four months. Merrill-Palmer Quarterly of Behavior and Development, 26(4), 321-339.

Beebe, B., Jaffe, J., Feldstein, S., Mays, K., \& Alson, D. (1985). Interpersonal timing: The application of an adult dialogue model to mother-infant vocal and kinesic interactions. In T. Field \& N. Fox (Eds.), Social perception in infants (pp. 217-247). Norwood, NJ: Ablex.

Beebe, B., Lachman, F., \& Jaffe, J. (1997). Motherinfant interaction structures and presymbolic self- and object representations. Psychoanalytic Dialogues: The International Journal of Relational Perspectives, 7(2), 133-182. doi:10.1080/10481889709539172

Beebe, B., Stern, D., \& Jaffe, J. (1979). The kinesic rhythm of mother-infant interactions. In A. W. Siegman \& S. Feldstein (Eds.), Of speech and time: Temporal patterns in interpersonal contexts (pp. 23-34). Hillsdale, NJ: Lawrence Erlbaum.

Birdwhistell, R. L. (1952). Introduction to kinesics: An annotation system for analysis of body motion and gesture. Washington, DC: Department of State, Foreign Service Institute.

Borstein, H. M., \& Tamis-LeMonda, C. (2010). MotherInfant interactions. In G. Bremner \& A. Fogel (Eds.), Blackwell Handbook of infant development (pp. 269295). Cornwell, Great Britain, TJ International.

Brand, R. J., Baldwin, D. A., \& Ashburn, L. A. (2002). Evidence for 'motionese': Modifications in mothers' infant-directed action. Developmental Science, 5(1), 7283. doi:10.1111/1467-7687.00211

Brazelton, T. B., Koslowski, B., \& Main, M. (1974). The origins of reciprocity: The early mother-infant interaction. In M. Lewis \& L. A. Rosenblum (Eds.), The effect of the infant on its caregiver (pp. 49-76). New York, NY: WileyInterscience.
Bruner, J. S. (1996). The culture of education. Cambridge, MA: Harvard University Press.

Bull, P. (2003). The microanalysis of political communication. London, UK: Routledge.

Bremner, A. J., Lewkowicz, D. J., \& Spence, C. (2012). Multisensory development. Oxford, UK: Oxford University Press.

Cooper, H., Hedges, L.V. \& Valentine, J.C. (Eds.) (2009). The handbook of research synthesis and meta-analysis (2th ed.). New York: Russell Sage Foundation.

Condon, W. S. (1970). Method of micro-analysis of sound films of behavior. Behavior Research Methods \& Instrumentation, 2(2), 51-54. doi:10.3758/BF03210994

Condon, W. S. (1976). An analysis of behavioral organization. Sign Language Studies, 13, 285-318. doi:10.1353/ sls. 1976.0001

Condon, W. S. (1980). The relation of interactional synchrony to cognitive and emotional processes. In M. R. Key (Ed.), The relationship of verbal and non-verbal communication (pp. 49-65). The Hague, Netherlands: Mouton.

Condon, W. S., \& Ogston, W. D. (1966). Sound film analysis of normal and pathological behavior patterns. Journal of Nervous and Mental Disease, 143(4), 338-347. doi:10.1097/00005053-196610000-00005

Condon, W. S., \& Ogston, W. D. (1967). A segmentation of behavior. Journal of Psychiatric Research, 5(3), 221-235. doi:10.1016/0022-3956(67)90004-0

Condon, W. S., \& Sander, L. W. (1974). Synchrony demonstrated between movements of the neonate and adult speech. Child Development, 45(2), 456-462. doi:10.2307/1127968

Delafield-Butt, J. T., \& Trevarthen, C. (2013). Theories of the development of human communication. In P. Cobley \& P. J. Schultz (Eds.), Theories and models of communication (pp. 199-222). Berlin, Germany: De Gruyter Mouton.

Delafield-Butt, J. T., \& Trevarthen, C. (2015). The ontogenesis of narrative: from moving to meaning. Front. Psychol. 6:1157. doi: 10.3389/fpsyg.2015.01157

Dissanayake, E. (2000). Art and intimacy. Seattle, WA: University of Washington Press.

Dissanayake, E. (2009). Bodies swayed to music: The temporal arts as integral to ceremonial ritual. In S. Malloch \& C. Trevarthen (Eds.), Communicative musicality: Exploring the basis of human companionship (pp. 533-544). Oxford, UK: Oxford University Press.

Español, S., Bordoni, M., Martínez, M., Camarasa, R., \& Carretero, S. (2015). Forms of vitality play and symbolic play during the third year of life. Infant Behavior \& Development, 40, 242-251. doi:10.1016/j. infbeh.2015.05.008

Español, S., Martínez, M., Bordoni, M., Camarasa, R., \& Carretero, S. (2014). Forms of vitality play in infancy. Integrative Psychological \& Behavioral Science, 48(4), 479-502. doi:10.1007/s12124-014-9271-5

Español, S., \& Shifres, F. (2015). The artistic infant directed performance: A microanalysis of the adult's movements 
and sounds. Integrative Psychological \& Behavioral Science, 49(3), 371-397. doi:10.1007/s12124-015-9308-4

Feldstein, S., \& Welkowitz, J. (1978). A chronography of conversation: In defense of an objective approach. In A. W. Siegman \& S. Feldstein (Eds.), Nonverbal behavior and communication (pp. 329-378). Hillsdale, NJ: Taylor $\&$ Francis Group.

Fernández-Ríos, L. \& Buela-Casal, G. (2009). Standards for the preparation and writing of Psychology review articles. International Journal of Clinical and Health Psychology, 9(2), 329-344.

Fogel, A. (1977). Temporal organization in mother-infant face-to-face interaction. In H. R. Schaffer (Ed.), Studies in mother-infant interaction: Proceedings of the Loch Lomond Symposium (pp. 119-152). London, UK: Academic Press.

Fogel, A. (1992). Movement and communication in human infancy. Human Movement Science, 11(4), 387-423. doi:10.1016/0167-9457(92)90021-3

Fogel, A., Dedo, J. Y., \& McEwen, I. (1992). Effect of postural position and reaching on gaze during mother-infant faceto-face interaction. Infant Behavior \& Development, 15(2), 231-244. doi:10.1016/0163-6383(92)80025-P

Fogel, A., de Koeyer, I., Bellagamba, F., \& Bell, H. (2002). The dialogical self in the first two years of life: Embarking on a journey of discovery. Theory \& Psychology, 12(2), 191-205. doi:10.1177/0959354302012002629

Fogel, A., \& Garvey, A. (2007). Alive communication. Infant Behavior \& Development, 30(2), 251-257. doi:10.1016/j. infbeh.2007.02.007

Gibson, E. J. (1969). Principles of perceptual learning and development. New York, NY: Appleton-Century-Crofts.

Gomila, A. (2003). La perspectiva de segunda persona de la atribución mental [The second person perspective of mental attribution]. In A. Duarte \& E. Rabossi (Eds.), Psicología cognitiva y filosofía de la mente: Representación y conciencia [Cognitive psychology and philosophy of mind] (pp. 195-218). Buenos Aires, Argentina: Alianza.

Gratier, M., \& Apter-Danon, G. (2009). The improvised musicality of belonging: Repetition and variations in mother-infant vocal interaction. In S. Malloch \& C. Trevarthen (Eds.), Communicative musicality: Exploring the basis of human companionship (pp. 301-328). Oxford, UK: Oxford University Press.

Hinde, R. A. (1974). Biological bases of human social behaviour. New York, NY: McGraw- Hill.

Jaffe, J., Beebe, B., Feldstein, S., Crown, C. L., Jasnow, M. D., Rochat, P., \& Stern, D. N. (2001). Rhythms of dialogue in infancy: Coordinated timing in development. Monographs of the Society for Research in Child Development, 66(2), i-149.

Jaffe, J., \& Feldstein, S. (1970). Rhythms of dialogue. New York, NY: Academic Press.

Johnson, M. (2007). The meaning of the body: Aesthetics of human understanding. Chicago, IL: University of Chicago Press.
Kendon, A. (1972). Some relationship between body motion and speech. An analysis of an example. In A. W. Siegman \& B. Pope (Eds.), Studies in dyadic communication (pp. 177-210). Elmsford, NY: Pergamon.

Kokkinaki,T.(2010). Intersubjectivity during freeinfant-father "protoconversation" and within-"protoconversation" pauses. Early Child Development and Care, 180(1-2), 87-106. doi:10.1080/03004430903414737

Konner, M. J. (1972). Aspects of developmental ethology of a foraging people. In N. B. Jones (Ed.), Ethological studies of child behaviour (pp. 285-304). Cambridge, MA: Cambridge University Press.

Koterba, E. A., \& Iverson, J. M. (2009). Investigating motionese: The effect of infant-directed action on infants' attention and object exploration. Infant Behavior \& Development, 32(4), 437-444. doi:10.1016/j. infbeh.2009.07.003

Lakoff, G., \& Johnson, M. (1980). Metaphors we live by. Chicago, IL: University of Chicago Press.

Lieven, E., \& Stoll, S. (2013). Early communicative development in two cultures: A comparison of the communicative environments of children from two cultures. Human Development, 56, 178-206. doi:10.1159/000351073

Licata, M., Paulus, M., Thoermer, C., Kristen, S., Woodward, A., \& Sodian, B. (2014). Mother-infant interaction quality and infants' ability to encode actions as goal-directed. Social Development, 23(2), 340-356. doi:10.1111/ sode. 12057

Malloch, S., \& Trevarthen, C. (Eds.). (2009). Communicative musicality: Exploring the basis of human companionship. Oxford, England: Oxford University Press.

Martínez, I. (2014). La base corporeizada del significado musical [The corporeal basis of musical meaning]. In S. Español (Org.), Psicología de la música y Psicología del desarrollo. Una exploración interdisciplinaria sobre la musicalidad humana [Psychology of music and developmental psychology. An interdisciplinary exploration of human musicality] (pp. 71-106). Buenos Aires, Argentina: Paidós.

Meltzoff, A. N., \& Borton, R. W. (1979). Intermodal matching by human neonates. Nature, 282(5737), 403404. doi: $10.1038 / 282403 \mathrm{a} 0$

Needham, A., \& Libertus, K. (2011). Embodiment in early development. Cognitive Science, 2(1), 117-123. doi:10.1002/wcs.109

Negayama, K., Delafield-Butt, J. T., Momose, K., Ishijima, K., Kawahara, N., Lux, E. J., Kaliarntas, K. (2015). Embodied intersubjective engagement in mother-infant tactile communication. Frontiers in Psychology, 6, 66. doi:10.3389/fpsyg.2015.00066

Pérez, D. (2013). Sentir, desear, creer. Una aproximación filosófica a los conceptos psicológicos [Feeling, desiring, believing. A philosophical approach to psychological concepts]. Buenos Aires, Argentina: Prometeo.

Perinat, A. (1980). Contribuciones de la etología al estudio 
del desarrollo humano y socialización [Contributions of ethology to the study of human development and socialization]. El Basilisco, 11, 27-34.

Reddy, V. (2008). How infants know minds. Cambridge, MA: Harvard University Press.

Spelke, E. S. (1979). Perceiving bimodally specified events in infancy. Developmental Psychology, 15(6), 626-636. doi:10.1037/0012-1649.15.6.626

Stern, D. N. (1974a). The goal and structure of motherinfant play. Journal of the American Academy of Child Psychiatry, 13(3), 402-421. doi:10.1016/S00027138(09)61348-0

Stern, D. N. (1974b). Mother and infant at play: The dyadic interaction involving facial, vocal, and gaze behaviors. In M. Lewis \& L. A. Rosenblum (Eds.), The effect of the infant on its caregiver (pp. 187-214). New York, NY: Wiley.

Stern, D. N. (1977). The first relationship: Infant and mother. Cambridge, MA: Harvard University Press.

Stern, D. N. (2010). Forms of vitality: Exploring dynamic experience in psychology, arts, psychotherapy, and development. Oxford, UK: Oxford University Press.

Stern, D. N., Beebe, B., Jaffe, J., \& Bennett, S. L. (1977). The infant's stimulus world during social interaction. In H. R. Schaffer (Ed.), Studies in mother-infant interaction: Proceedings of the Loch Lomond Symposium (pp. 177202). London, UK: Academic Press.

Stern, D. N., Jaffe, J., Beebe, B., \& Bennett, S. L. (1975). Vocalizing in unison and alternation: Two modes of communication within the mother-infant dyad. Annals of the New York Academy of Sciences, 263, 89-100. doi:10.1111/j.1749-6632.1975.tb41574.x

Thelen, E. (2000). Grounded in the world: Developmental origins of the embodied mind. Infancy, 1(1), 3-28. doi:10.1207/S15327078IN0101_02

Soledad Carretero Pérez is a Postdoctoral scholarship holder at Consejo Nacional de Investigaciones Científicas y Técnicas.

Silvia Ana Español is a Researcher at Consejo Nacional de Investigaciones Científicas y Técnicas.

Received: Aug. 19, 2015

1st Revision: Dec. 22, 2015

Approved: Dec. 29, 2015

How to cite this article:

Carretero Pérez, S., \& Español, S. (2016). The multimodal study of adult-infant interaction: A review of its origins and its current status. Paidéia (Ribeirão Preto), 26(65), 377-385. doi:10.1590/1982-43272665201613 